\title{
Comparative Study of Microscopy and Polymerase Chain Reaction for the Diagnosis of Suspected Visceral Leishma- niasis Patients in Nepal
}

\author{
Pandey K, ${ }^{1}$ Mallik AK, ${ }^{2}$ Pyakurel S, ${ }^{3}$ Pun $\mathrm{SB},{ }^{4}$ Pandey $\mathrm{BD}^{1,4}$
}

${ }^{1}$ Everest International Clinic and Research Center Kathmandu, Nepal

2Janakpur Zonal Hospital, Janakpur, Nepal

${ }^{3}$ University Centre for Rural Health, North Coast Sydney School of Public Health, The University of Sydney, Australia

${ }^{4}$ Sukraraj Tropical and Infectious Disease Hospital Kathmandu, Nepal

Corresponding Author

Kishor Pandey

Everest International Clinic and Research Center Kathmandu, Nepal

Email: pandey_kishor@hotmail.com

Citation

Pandey K, Mallik AK, Pyakurel S, Pun SB, Pandey BD. Comparative Study of Microscopy and Polymerase Chain Reaction for the Diagnosis of Suspected Visceral Leishmaniasis Patients in Nepal. Kathmandu Univ Med J 2013;41(1):14-17 .

\begin{abstract}
Background

Visceral leishmaniasis is potentially fatal protozoan diseases caused by Leishmania donovani. Nepal is an endemic region in which visceral leishmaniasis causes a major public health problem in the lowland areas that border the endemic areas of Bihar state in India. Accurate diagnosis to inform treatment is a first step in achieving the goal of visceral leishmaniasis elimination from South East Asian regions by 2020.

\section{Objective}

The objective of the present study was to compare between the Microcopy and polymerase chain reaction for diagnosis of visceral leishmaniasis.

\section{Methods}

In the present study, 236 bone marrow aspirations were collected from suspected visceral leishmaniasis patients in Janakpur Zonal Hospital, Dhanusa district, Terai region of Nepal in between 2003-2007. We evaluated bone marrow samples by microscopic examination with subsequent testing of the same sample by polymerase chain reaction and sequence analysis.

\section{Results}

Giemsa's solution stained bone marrow slides stored for over five years were used for polymerase chain reaction amplification. The result showed that $71 \%$ were polymerase chain reaction positive and $56 \%$ were microscopic positive. Out of 104 microscopic negative bone marrow samples, $15 \%$ of samples were positive by polymerase chain reaction.

\section{Conclusion}

Polymerase chain reaction could make a very good option for diagnosis by using less or non-invasive material from visceral leishmaniasis patients in endemic areas of Nepal.

\section{KEY WORDS}

Diagnosis, microscopy, Nepal, polymerase chain reaction, visceral leishmaniasis

\section{INTRODUCTION}

Visceral leishmaniasis (VL) is a vector borne disease caused by the protozoan parasite, Leishmania donovani and transmitted by the bite of female sandfly, Phlebotomus argentipes. It occurs in more than 80 countries in Asia, Africa, Southern Europe and South America, with a total of 200 million people at risk. ${ }^{1}$ However, $90 \%$ of the estimated 500,000 new symptomatic cases per year mainly arise in five countries; Nepal, India, Sudan, Bangladesh and Brazil. ${ }^{2}$
Visceral leishmaniasis is the one of the major public health problems in Nepal. It occurs especially among the socially marginalized and poorest communities. Altogether 13 districts in the Eastern and Central Terai regions bordering the northern state of Bihar are endemic for VL (Fig 1). The disease can be fatal if not properly treated. Clinical diagnosis does not suffice for the definitive management of VL. Hence, laboratory diagnosis is important. ${ }^{3}$ Until 


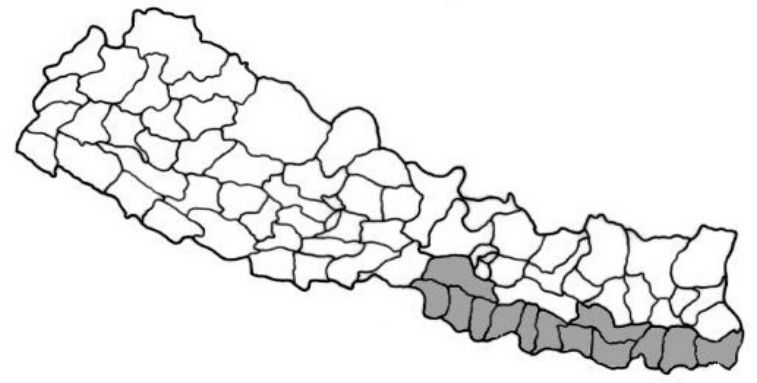

Figure 1. District map of Nepal showing endemic area for visceral leishmaniasis which are indicated in gray color.

recently, VL diagnosis was complex and invasive (direct microscopic examination of spleenic or bone marrow aspirate). Laboratory diagnosis of VL in Nepal usually relies on serological diagnosis (rK39 dipstick test). Microscopic examination for Leishman-Donovan bodies (LD bodies) is performed in some referral centers, and a very small number of properly equipped laboratories can perform polymerase chain reaction (PCR).

PCR has several advantages including the ability to detect very small amount of target materials and rapid detection in symptomatic patients and asymptomatic carriers. Some centers use other serological methods (ELISA, DAT) as additional tests. The aim of the present study is to compare two methods, microscopy and PCR, for VL diagnosis.

\section{METHODS}

A total 236 bone marrow samples were collected between 2003 and 2007 from suspected visceral leishmaniasis patients in Janakpur Zonal Hospital, Dhanusa district, Terai region of Nepal. Visceral leishmaniasis was suspected when a patient from a VL endemic area presents with a history of fever for more than two weeks, weight loss and a palpable spleen were presented in the hospital. Bone marrow (BM) was aspirated in clinically suspected patients. BM smears were prepared on glass slides, fixed with methanol and stained with Giemsa's solution. The slide was observed under a microscope to detect Leishman Donovan (LD) bodies.Slides were kept at room temperature and shipped to Japan for molecular analysis. Informed consent from each of the patients was obtained before aspiration of bone marrow. The research protocol was approved by the Ethical Committee of Nagasaki University.

Bone marrow smears were re-examined microscopically for detection of LD body and were used for DNA extraction. BM smears were wiped with paper wipes to remove immersion oil, wetted with sterile phosphate-buffered saline, and scraped with a sterile scalpel. The BM smears were transferred into $1.5 \mathrm{ml}$ tube. The DNA was extracted by using the DNeasy Blood and Tissue Kit (Qiagen, Valencia, $\mathrm{CA})$ according to the manufacturer's instructions. A final volume $50 \mu$ of DNA was extracted and stored at $-20^{\circ} \mathrm{C}$ for further analysis. DNA was also extracted from in vitro cultured parasites for use as a positive control and to check the specificity and sensitivity of PCR amplification.

A conserved region of minicircle kinetoplast DNA was selected for PCR amplification as it is present at high copy numbers $\left(10^{4}\right.$ per parasite), maximizing the possibility of detection of a single parasite. ${ }^{4}$ PCR analysis consisted of two steps as previously reported. ${ }^{5}$ Briefly, first-round PCR amplification was carried out in a total of $10 \mu \mathrm{l}$ reaction mixture containing Nova Taq Hot start DNA polymerase, Ampdirect plus (Containing $\mathrm{MgCl} 2$ and dNTPs), primers LINR4 (5'-GGGGTTGGTGTAAAATAGGG-3') and LIN17 (5'TTTGAACGGGATTTCTG-3') and $2 \mu$ of target DNA solution. The mixture was incubated at $94^{\circ} \mathrm{C}$ for $5 \mathrm{~min}$ followed by 17 cycles, each consisting of $30 \mathrm{~s}$ at $94^{\circ} \mathrm{C}, 30 \mathrm{~s}$ at 52 ${ }^{\circ} \mathrm{C}$ and $30 \mathrm{~s}$ at $72{ }^{\circ} \mathrm{C}$. After the last cycle, the extension was continued for a further $10 \mathrm{~min}$ then held at $4{ }^{\circ} \mathrm{C}$. The second-round PCR was carried out in a $20-\mu$ l reaction mixture with addition of Amp direct plus and Nova Taq Hot start DNA polymerase (as described for the first-step), primer LIN19 (5'-CAGAACGCCCCTACCCG-3'), and $1 \mu \mathrm{l}$ of DNA solution (first PCR product) for 33 cycles $\left(94{ }^{\circ} \mathrm{C}\right.$ for 30 $\mathrm{s}, 58{ }^{\circ} \mathrm{C}$ for $30 \mathrm{~s}$ and $72{ }^{\circ} \mathrm{C}$ for $1 \mathrm{~min}$ ). Cross-contamination was monitored by negative control and positive control in each experiment. Positive controls contained DNA solution extracted from cultured L. donovani parasites. Ten microliters of the PCR-amplified products were subjected to $2 \%$ agarose gel electrophoresis, stained with ethidium bromide, and visualized under UV light. A 100-bp DNA ladder was used as a marker.

A total of $12(5 \%)$ of samples were randomly selected for sequencing. After agarose gels electrophoresis, DNA fragments were cut and purified by using the QIAquick gel extraction kit (Qiagen). Purified DNA fragments were directly sequenced using an ABI Prism BigDye ${ }^{\circledR}$ Termanitor v1.1 Cycle Sequencing Kit (Applied Biosystem, USA) according to the manufacturer's instruction.

Data was analyzed using WIN PEPI software (version 7.9, November 24, 2008). The analysis was performed by using Chi-square $(\chi 2)$ test and statistical significance was accepted for $\mathrm{p}<0.05$.

\section{RESULTS}

All the collected samples underwent microscopic examination at Janakpur Zonal Hospital, Janakpur, Nepal. Samples from 236 suspected VL patients who had visited hospitals in different parts of the Terai region were examined by two different diagnostic techniques (Microscopy and PCR). The obtained results with each technique are given in table 1 . Out of 236 Giemsa stained bone marrow slides examined microscopically, 132 (56\%) were positive and 104 (44\%) were negative for LD body. All the samples were observed in Nagasaki University for further confirmation. Microscopic positive and negative 
Table 1. Comparison between Microscopic and PCR for the diagnosis of visceral leishmaniasis.

\begin{tabular}{|lllll|} 
& Microscopy (+) & Microscopy (-) & Total & Statistic \\
\hline PCR (+) & 132 & 35 & 167 & $x 2=123.761$ \\
\hline PCR (-) & 0 & 69 & 69 & $p<0.0001$ \\
\hline Total & 132 & 104 & 236 & \\
\hline
\end{tabular}

Table 2. Demographic profile of patients.

\begin{tabular}{|llll|}
\hline & PCR (+) & Microscopic (+) & $\begin{array}{l}\text { PCR (+) / } \\
\text { Microscopic (-) }\end{array}$ \\
\hline Gender & & & \\
\hline Male & 105 & 86 & 19 \\
\hline Female & 62 & 46 & 16 \\
\hline Total & 167 & 132 & 35 \\
\hline Age (Years) & & & \\
\hline$<15$ & 51 & 14 & 10 \\
\hline $16-25$ & 41 & 35 & 6 \\
\hline $26-35$ & 36 & 27 & 9 \\
\hline $36-45$ & 15 & 13 & 2 \\
\hline$>46$ & 24 & 16 & 8 \\
\hline Total & 167 & 132 & 35 \\
\hline
\end{tabular}

bone marrow samples were further analyzed by seminested PCR. The PCR result showed that 167 (70.8\%) were positive for visceral leishmaniasis. Sixty nine (28.2\%) were negative for both PCR and microscopy. All the samples which were positive by microscopy were also positive by PCR. Out of $10^{4}$ microscopic negative samples, 35 (15\%) were positive by PCR. A statistically significant difference was found between PCR and microscopy method for diagnosis of $V L$ in Nepal $(\chi 2=123.761, p=0.0001)$. The demographic profiles of patients are given in table 2 . Out of $236 \mathrm{VL}$ suspected patients, 135 (57\%) were male and 101 $(43 \%)$ were female. The patients age were ranged from one year to 80 year.

In vitro culture samples were used to check the specificity and sensitivity of the primers used in the semi-nested PCR. Promastigotes of $L$. donovani were cultured in vitro as described previously and the parasites were reconstituted into 104 parasites per $\mathrm{ml}$ aliquots in phosphate buffered saline (PBS). ${ }^{6}$ A Neubauer Chamber (a haemocytometer) was used to count culture parasites. Ten-fold serial dilutions of the culture were made $\left(10^{3}, 10^{2}, 10^{1}\right.$, and 1 parasite per $\mathrm{ml}$ ) in duplicate. DNA was extracted from each serial diluted culture parasite and PCR was performed. PCR results showed that a single culture parasite was detectable by this method (Fig 2). PCR was subsequently performed for bone marrow smears fixed with Giemsa's solution. Samples which produced a 720-bp band following PCR amplification and electrophoresis were judged to be positive. Fig 3 shows an example of an agarose gel electrophoresis image. The positive controls produced the expected 720-bp band which was absent from the negative controls. The PCR products were directly sequenced and

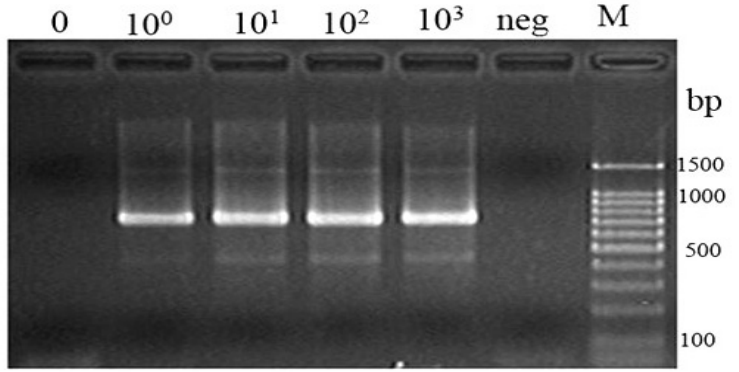

Figure 2. Sensitivity of the PCR with different number of parasites (0 parasite to 1000 parasites), neg-Negative, M-100 bp marker.

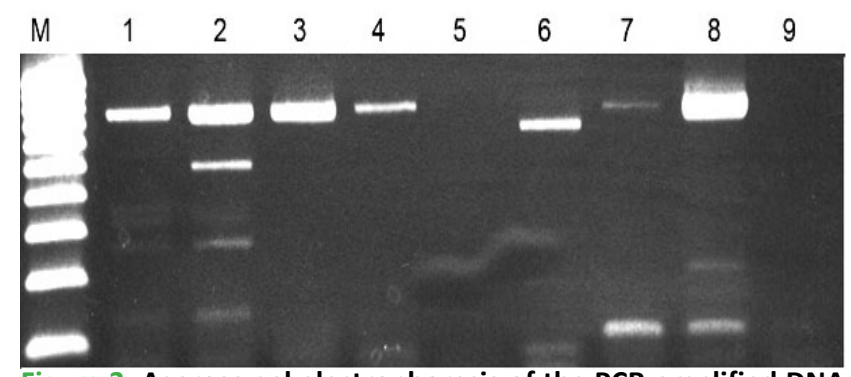

Figure 3. Agarose gel electrophoresis of the PCR-amplified DNA fragments (Lane $M, 100$ bp marker; lane 1-7, bone marrow samples; lane 8, positive control; lane 9, Negative control).

compared with known sequences to confirm the species identification $L$. donovani. All the selected samples were identified as $L$. donovani based on the strong homology with reported kDNA sequence (data not shown). ${ }^{7}$

\section{DISCUSSION}

Microscopic examination of Giemsa's solution-stained bone marrow smears remains the gold standard method for VL diagnosis due to its high sensitivity. However, in Nepal, this type of diagnostic service is available only at level III health institutions and a special referral hospital. The method is simple, and does not require expensively equipped facilities. However, in most cases it is very difficult to find LD bodies. In addition, microscopy is often time-consuming and laborious to perform. This method can sometimes be misleading in identifying the parasite correctly, leading to inappropriate management of cases. Presently the national guidelines state that it is essential to start treatment for VL in a clinically suspected case with a positive rK39 test. The rK39 is a very important screening test but it gives false negative results in the early acute stage of the disease and it does not differentiate between active, past, or subclinical infection. It remains positive well beyond the time of cure, thus limiting its use for the diagnosis of relapse or re-infection. ${ }^{8}$ PCR has proven to be a more sensitive diagnostic method than microscopy, particularly in cases of low parasite number. PCR can detect parasite DNA even in cases with a very low number of parasites, where microscopy results were negative. However, PCR would be useful in discriminating the low parasite infection cases strongly suspected by the clinicians but not supported by microscopy, and hence could be an important diagnosis tool. 
Giemsa's solution stained bone marrow smears on glass slides are very valuable sources of DNA for PCR diagnosis. Firstly, PCR diagnosis using DNA extracted from Giemsa's stained bone marrow slides is a suitable method to confirm diagnosis for VL patients. Secondly, it is very useful in the diagnosis of difficult cases. Thirdly, bone marrow smears can be easily stored at room temperature for long time and can be performed PCR anytime in future.

PCR-based Leishmania diagnosis from bone marrow smears on glass slides have not been widely applied, although we have recently described the use of this strategy. ${ }^{9}$ Correct diagnosis and identification of Leishmania species is essential for choosing the correct and effective treatment and for the production of effective vaccines. ${ }^{10}$ With the increasing incidence of drug resistance in endemic areas, early case-finding and accurate diagnosis for effective treatment is an essential component of VL control and is necessary in order to interrupt the cycle. In the past decade, DNA-based methods have been used for diagnosis and identification of Leishmania species. Detection of the Leishmania parasites by PCR methods is highly sensitive with specificity approaching $100 \%{ }^{11}$

The overall cost calculated for one PCR assay starting from DNA isolation was approximately RS 500 (less than $\$ 6)$, comparable with the cost of one rK39 strip (\$5). A basic molecular biological lab is required with minimum infrastructure; a thermo cycler; a UV trans-illuminator and a gel electrophoresis unit are one time investment and if they can be provided, PCR could be performed in an endemic setting for routine diagnosis.

\section{CONCLUSION}

PCR is a good option for specific diagnosis of clinically obtained samples and this technique should decentralize to at least the district level of endemic areas where one PCR laboratory with capability to perform PCR could make confidential diagnoses. It is essential to develop less invasive (blood) or non-invasive (buccal swab or urine) methods as source for PCR analysis to optimize VL diagnosis in endemic countries. The results of this study indicate that $\mathrm{PCR}$ analysis is superior to microscopy for definite diagnosis of VL.

\section{ACKNOWLEDGEMENT}

The author thanks patients and patients' family who are enrolled in the study. The author was thankful to Dr. Richard Culleton (Nagasaki University) for critically reading manuscript.

\section{REFERENCES}

1. Murray HW. Clinical and experimental advances in treatment of visceral leishmaniasis. Antimicrob Agents Chemother 2001 Aug;45(8):2185-97.

2. Arias JR, Monteiro PS and Zicker F. The re-emergence of visceral leishmaniasis in Brazil. Emerg Infect Dis 1996 Apr-Jun;2(2):145-6.

3. Sundar S and Rai M. Advances in the treatment of leishmaniasis. Curr Opin Infect Dis 2002 Dec;15(6):593-8.

4. Akkafa F, Dilmec F, Alpua Z. Identification of Leishmania parasites in clinical samples obtained from cutaneous leishmaniasis patients using PCR-RFLP technique in endemic region, Sanliurfa province, in Turkey. Parasitol Res 2008 Aug;103(3):583-6.

5. Aransay AM, Scoulica E, Tselentis $Y$. Detection and identification of Leishmania DNA within naturally infected sand flies by seminested PCR on minicircle kinetoplastic DNA. Appl Environ Microbiol 2000 May;66(5):1933-8.

6. Pandey K, Yanagi T, Pandey BD, Mallik AK, Sherchand JB, Kanbara H. Characterization of Leishmania isolates from Nepalese patients with visceral leishmaniasis. Parasitol Res 2007 May;100(6):1361-9.

7. Basselin M, Badet-Denisot MA, Robert-Gero M. Modification of kinetoplast DNA minicircle composition in pentamidineresistant Leishmania. Acta Trop 1998 Jun 15;70(1):43-61.

8. Chappuis F, Sundar S, Hailu A, Ghalib H, Rijal S, Peeling RW et al. Sceral leishmaniasis: what are the needs for diagnosis, treatment and control? Nat Rev Microbiol 2007 Nov;5(11):873-82.

9. Pandey K, Pandey BD, Mallik AK, Kaneko O, Uemura H, Kanbara H et.al. Diagnosis of visceral leishmaniasis by polymerase chain reaction of DNA extracted from Giemsa's solution-stained slides. Parasitol Res 2010 Aug;107(3):727-30.

10. El Tai NO, Osman OF, El Fari M, Presber WH, Schonian G. Genetic heterogeneity of ribosomal internal transcribed spacer (ITS) in clinical samples of Leishmania donovani spotted on filter paper as revealed by single strand conformation polymorphisms and sequencing. Trans R Soc Trop Med Hyg 2000 Sep-Oct;94(5):575-9.

11. Garcia AL, Kindt A, Quispe-Tintaya KW, Bermudez H, Llanos A, Arevalo $\mathrm{J}$ et al. American tegumentary leishmaniasis: antigen-gene polymorphism, taxonomy and clinical pleomorphism. Infect Genet Evol 2005 Mar;5(2):109-16. 